\title{
Evaluation of aluminum ultralight rigid wheelchairs versus other ultralight wheelchairs using ANSI/RESNA standards
}

\author{
Hsin-yi Liu, MS; ${ }^{1}$ Jonathan Pearlman, PhD; ${ }^{1}$ Rosemarie Cooper, MPT; ${ }^{1-2}$ Eun-kyoung Hong, MS; ${ }^{1}$ Hongwu \\ Wang, MS ; ${ }^{1}$ Benjamin Salatin, BS; ${ }^{1}$ Rory A. Cooper, PhD ${ }^{1,3-4 *}$ \\ ${ }^{1}$ Human Engineering Research Laboratories, Department of Veterans Affairs (VA), Rehabilitation Research \& Devel- \\ opment Service, VA Pittsburgh Healthcare System, Pittsburgh, PA; and Department of Rehabilitation Sciences and \\ Technology, University of Pittsburgh, Pittsburgh, PA; ${ }^{2}$ Center for Assistive Technology, University of Pittsburgh Medi- \\ cal Center, Pittsburgh, PA; ${ }^{3}$ Department of Bioengineering, University of Pittsburgh, Pittsburgh, PA; ${ }^{4}$ Department of \\ Physical Medicine and Rehabilitation, University of Pittsburgh, Pittsburgh, PA
}

\begin{abstract}
Previous studies found that select titanium ultralight rigid wheelchairs (TURWs) had fewer equivalent cycles and less value than select aluminum ultralight folding wheelchairs (AUFWs). The causes of premature failure of TURWs were not clear because the TURWs had different frame material and design than the AUFWs. We tested 12 aluminum ultralight rigid wheelchairs (AURWs) with similar frame designs and dimensions as the TURWs using the American National Standards Institute/Rehabilitation Engineering and Assistive Technology Society of North America and International Organization for Standardization wheelchair standards and hypothesized that the AURWs would be more durable than the TURWs. Across wheelchair models, no significant differences were found in the test results between the AURWs and TURWs, except in their overall length. Tire pressure, tube-wall thickness, and tube manufacturing were proposed to be the factors affecting wheelchair durability through comparison of the failure modes, frames, and components. The frame material did not directly affect the performance of AURWs and TURWs, but proper wheelchair manufacture and design based on mechanical properties are important.
\end{abstract}

Key wo rds: aluminum wheelchair, ANSI/RESNA, durability, fatigue life, fatigue mode, manual wheelchair, titanium wheelchair, ultralight wheelchair, wheelchair, wheelchair standards.

\section{INTRODUCTION}

Clinical guidelines recommend ultralight wheelchairs as the most appropriate wheelchairs for active manual wheelchair users [1]. The reduced weight of ultralight manual wheelchairs helps preserve users' upper-limb function by reducing the force required to

\footnotetext{
Abbreviations: ANSI = American National Standards Institute, AUFW = aluminum ultralight folding wheelchair, AURW = aluminum ultralight rigid wheelchair, CDT = curb-drop test, $\mathrm{CoG}=$ center of gravity, $\mathrm{CV}=$ coefficient of variation, DDT = double-drum test, $\mathrm{EC}=$ equivalent cycles, FDA = U.S. Food and Drug Administration, HERL = Human Engineering Research Laboratories, ISO = International Organization for Standardization, OEM = original equipment manufacturer, RESNA = Rehabilitation Engineering and Assistive Technology Society of North America, SD = standard deviation, TURW = titanium ultralight rigid wheelchair, VA = Department of Veterans Affairs.

${ }^{*}$ Address all corr espondence to $\mathrm{R}$ ory $\mathrm{A}$. Coo per, PhD; Human Engineering Research Laboratories (151R-1H), VA Pittsburgh Healthcare System, 7180 Highland Drive, Pittsburgh, PA 15206; 412-954-5287; fax: 412-954-5340.

Email: rcooper@pitt.edu

DOI:10.1682/JRRD.2009.08.0137
} 
propel a wheelchair, and ultralight wheelchairs are more durable and may be adjusted to meet each user's individual needs [1]. An estimated 1.5 million people in the United States use manual wheelchairs, and 37 percent of manual wheelchair users are adults of working age [2]. According to a study on veterans by Fitzgerald et al., more than 95 percent of active manual wheelchair users use ultralight wheelchairs [3]. With such a large population of potential ultralight wheelchair users, the performance and quality of ultralight wheelchairs draw attention from manufacturers and clinicians.

Manual wheelchairs are classified as "Class 1" medical devices by the U.S. Food and Drug Administration (FDA) [4] and are subject to general control and premarket notification requirements, also known as $510(\mathrm{k})$ requirements [5-6]. 510(k) guidelines require performance testing; however, they neither specify the organization that should conduct the tests nor make the Rehabilitation Engineering and Assistive Technology Society of North America (RESNA) standards a requirement [7-8]. Manufacturers and distributors may modify test methods and conduct tests themselves [8]. Insufficient emphasis and attention on the RESNA standards tests may lead to commercialized manual wheelchairs that have diverse or poor durability as revealed in previous studies [9-12]. FDA approval for manual wheelchairs does not assure their durability and performance. Medical insurers' prescription guidelines, mostly based on the Centers for Medicare and Medicaid Services, typically require a 3-to-5-year duration before a replacement wheelchair will be covered. Premature failure of wheelchairs could potentially injure users and require them to pay for replacements, which can be very expensive (several thousand dollars).

A 2001 study that compared wheelchair test results in the database of the Human Engineering Research Laboratories (HERL) concluded that ultralight manual wheelchairs had the longest fatigue life followed by lightweight manual wheelchairs and depot manual wheelchairs [13]. Although ultralight wheelchairs were more expensive than lightweight and depot wheelchairs, they were more cost-effective because of their longer fatigue life [9-11]. In addition, ultralight wheelchairs had a wide range of static stability because of their adjustable components, which make it possible to set up a manual wheelchair to fit a user's needs.

Aluminum is the most popular material for ultralight manual wheelchairs. It is cost-effective, has a higher strength-to-weight ratio than steel, and does not require specialized manufacturing equipment and techniques. Titanium has a higher strength-to-weight ratio than aluminum and is used widely in the aircraft and automobile industries for weight reduction [14]. However, it requires specialized techniques and equipment for machining, and the raw material is more expensive than aluminum and steel [15]. Thus, titanium wheelchairs are more expensive than steel and aluminum wheelchairs. Some basic mechanical properties of aluminum and titanium are shown in Table 1.

HERL recently conducted a study using the American National Standards Institute (ANSI)/RESNA wheelchair standards to evaluate select titanium ultralight rigid wheelchairs (TURWs) and compared the test results with previously tested aluminum ultralight folding wheelchairs (AUFWs). The TURWs were expected to show better performance and durability than the AUFWs because of the advances in science and technology that have been made recently. However, the study outcomes were different from the anticipated results [12].

The TURWs demonstrated less rearward static stability because they had a wider range of adjustability of the rear wheel axle position than the AUFWs [12]. Moving the rear wheel axle forward makes the wheelchair more responsive to turning and decreases the propulsion frequency and force required to initiate motion [16-17].

Table 1.

Mechanical properties of aluminum alloy 6061-T6 and titanium alloy Ti-6A1-4V [1-2].

\begin{tabular}{lcc}
\hline \multicolumn{1}{c}{ Property } & $\begin{array}{c}\text { Aluminum Alloy } \\
\text { 6061-T6 }\end{array}$ & $\begin{array}{c}\text { Titanium Alloy } \\
\text { Ti-6Al-4V }\end{array}$ \\
\hline $\begin{array}{l}\text { Density }\left(\mathrm{g} / \mathrm{cm}^{3}\right) \\
\text { Strength/Weight }\end{array}$ & 2.70 & 4.43 \\
$\quad$ Ratio $\left(\mathrm{MPa} \cdot \mathrm{cm}^{3} / \mathrm{g}\right)$ & 114 & 214 \\
Tensile Yield & 276 & 880 \\
$\quad$ Strength (MPa) & & \\
Ultimate Tensile & 310 & 950 \\
$\quad$ Strength $(\mathrm{MPa})$ & & \\
Shear Strength $(\mathrm{MPa})$ & 207 & 550 \\
Price $(\$ / \mathrm{kg})$ & 1.6 & 22.0 \\
\hline
\end{tabular}

1. MatWeb Material Property Data [Internet]. Blacksburg (VA): Automation Creations, Inc; 2009. [updated 2009; cited 2009]. Available from: http://www.matweb.com/search/search.aspx/.

2. Free Metal Price Charts [Internet]. Basalt (CO): MetalPrices.com; 2009 [cited 2009]. Available from: http://www.metalprices.com/pubcharts/. 
The average equivalent cycles (ECs) of each TURW model indicated that none of the four models in the study passed the fatigue standards: they were less durable with lower cost-effectiveness than previously tested AUFWs [12]. Nine out of twelve TURWs had premature catastrophic frame fractures. Although the test results revealed some engineering and design concerns within the TURWs, the direct durability comparison between TURWs and AUFWs was questionable because of their different frame designs, materials, and caster sizes [11-12].

The purpose of this study was to evaluate aluminum ultralight rigid wheelchairs (AURWs) using ANSI/ RESNA wheelchair standards, compare the test results among three ultralight wheelchair groups (AURWs, TURWs, and AUFWs), and investigate the effect of frame material (aluminum vs titanium) on ultralight wheelchairs. Four models of AURW were selected. We performed the tests from volume 1 of the ANSI/RESNA wheelchair standards [18] and part 3 of the International Organization for Standardization (ISO) wheelchair standards [19] to evaluate the AURWs. We hypothesized that the AURWs would demonstrate better durability than the TURWs (because manufacturers have more experience in designing and building aluminum wheelchairs) but show no difference in their dimensions, stability performance, and braking effectiveness (because they were both rigid frame wheelchairs of similar design). We also hypothesized that the AURWs would yield different results from the AUFWs on all of the RESNA standards tests because they were drastically different in frame design and caster sizes.

\section{METHODS}

\section{Tested Wheelchairs}

Twelve AURWs representing four models from four manufacturers were tested in this study: the TiLite AeroZ (TiLite; Kennewick, Washington), the Invacare Crossfire (Invacare; Elyria, Ohio), the Quickie GT (Sunrise Medical; Longmont, Colorado), and the Kuschall AirPro (Kuschall AG; Witterswil, Switzerland). Photographs of the four models in which one wheel of each model has been removed to show the frame design more clearly are in Figure 1. These models were the most popular AURWs prescribed at the Center for Assistive Technology at the University of Pittsburgh Medical Center and the Department of Veterans Affairs (VA) Prosthetic and
Sensory Aids Service and had similar frame designs as the previously tested TURWs. The wheelchairs were ordered with the same seat dimensions and specifications as the TURWs and set up with standard components of each model. Because of the cost and time involved in performing wheelchair standards tests, only three wheelchairs of each model were tested.

\section{Standards Tests}

We conducted the whole battery of ANSI/RESNA manual wheelchair standards tests [18]. Because the AURWs had similar frame designs and the same seat dimensions as the TURWs, we applied the modified methods and the testing setup used in the TURW comparison study [12] to test the AURWs.

To compare the tube strength among different tube dimensions and materials, we used the equation of yield stress $(Y)$ to calculate the estimated load at fracture $\left(F_{f}\right)$ when the load was applied at the midpoint of the specimen:

$$
\begin{gathered}
Y=\frac{F_{f} \times L}{\frac{I}{0.5 \times \mathrm{OD}}}, \\
I=\frac{\pi\left(\mathrm{OD}^{4}-\mathrm{ID}^{4}\right)}{64},
\end{gathered}
$$

where $I=$ area moment of inertia of tube shape, $L=$ length of the specimen, $\mathrm{OD}=$ tube outer diameter, and ID = tube inner diameter.

We assumed that the force was applied at the midpoint on each tube of $1 \mathrm{~m}$ in length; the estimated $F_{f}$ can be derived by the following equation:

$$
F_{f}=\frac{Y \times I \times \pi}{L \times 0.05 \times \mathrm{OD} \times 64}=\frac{Y\left(\mathrm{OD}^{4}-\mathrm{ID}^{4}\right) \pi}{32 \times \mathrm{OD}},
$$

The yield strength of aluminum alloy 6061-T6 (276 MPa) and titanium alloy Ti-6Al-4V (880 MPa) [20] were used to approximate the $F_{f}$ of the frame tube without screw holes for each model (in newtons). 


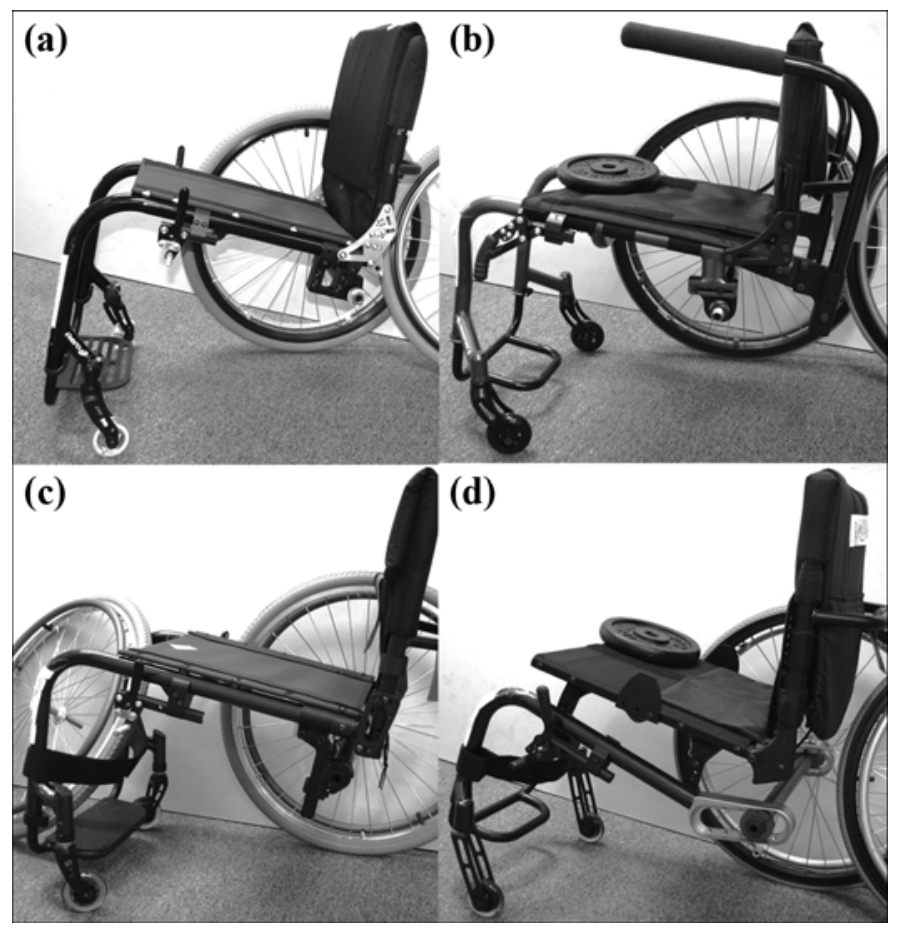

Figure 1.

Four models of aluminum ultralight rigid wheelchairs in this study: (a) TiLite AeroZ, (b) Invacare Crossfire, (c) Quickie GT, and (d) Kuschall AirPro.

\section{Static Stability}

The static stability tests (section 1 in the ANSI/ RESNA wheelchair standards) [18] measure the tipping angles of the wheelchair on a rising slope. The stability of the wheelchair was evaluated when it was set in its least and most stable configuration in the rearward and forward directions according to the standards. In the forward stability test, the wheelchair would tip forward when the platform was rising; in the rearward stability test, the wheelchair would tip backward. We applied the modified test method used in the previous study to accommodate rearward instability of rigid wheelchairs in the least stable setting [12]. Therefore, the wheelchair was placed facing downhill, resuming upright from a backward tilt position when the platform was rising; the platform angle when the front casters touched the platform was recorded.

\section{Braking Effectiveness}

The braking effectiveness test was performed according to part 3 of the ISO standards [19]. In the braking effectiveness test, wheelchairs were evaluated with the same settings as when they came out of the box and the rear wheel axle was set in the most rearward position. Braking effectiveness was quantified by measuring the angles at which the wheelchair started sliding on a rising slope.

\section{Brake Fatigue}

The brake fatigue test was also performed according to part 3 of the ISO standards [19]. To perform the brake fatigue test, we built a repetitive brake operating system according to the standard. A photograph of the system is shown in Figure 2. The system operated the brake from the brake-off position to the brake-on position and returned to the brake-off position 60,000 times at a frequency not exceeding $0.5 \mathrm{~Hz}$. The brake was adjusted according to manufacturer specifications. If the wheelchair manual did not specify the adjustment, the brake was adjusted to achieve a maximum operating force of $60 \pm$ $5 \mathrm{~N}$ as specified in the standard. Any movement of the brake assembly relative to the wheelchair structure and any change in brake performance were recorded.

\section{Impact and Static Strength}

In the impact and static strength tests (section 8 in the ANSI/RESNA wheelchair standards), the impact and static forces were applied to the parts of the wheelchair [18]. The forces are specified by the standards to simulate the possible impacts and static stresses that a wheelchair is exposed to in real use.

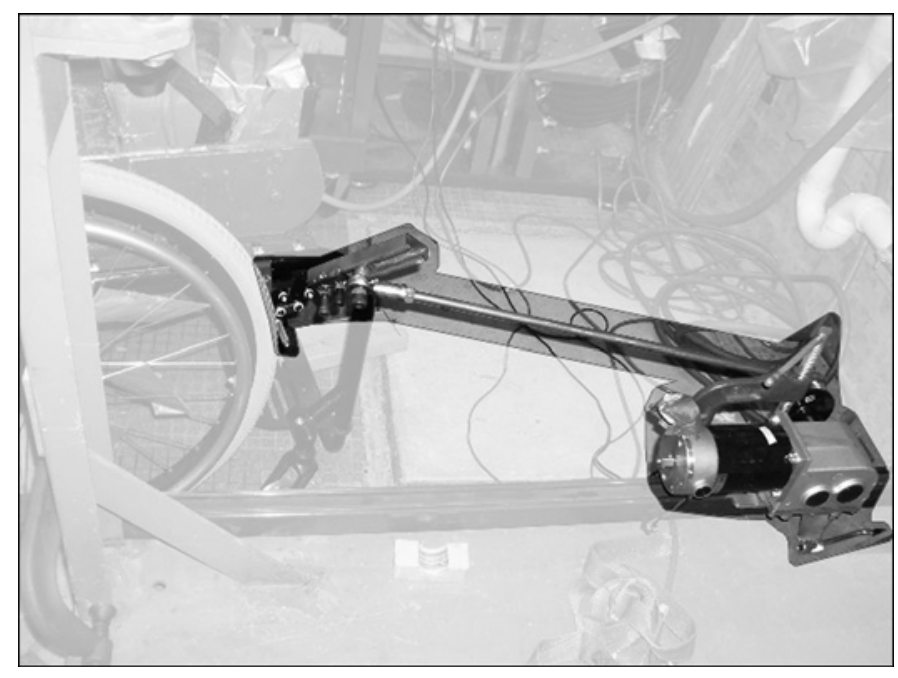

Figure 2.

Repetitive brake operating system for brake fatigue test. 


\section{Fatigue}

The fatigue tests (section 8 in the ANSI/RESNA wheelchair standards) consist of the double-drum and curb-drop tests (DDT and CDT, respectively) [18]. If a wheelchair passed both the DDT and CDT, we repeated the fatigue tests on the wheelchair until permanent damage occurred so we could compare life cycle and value across all the devices. To compare the durability across wheelchairs, we used the following formula to compute the ECs [12]:

$$
\text { Total } \mathrm{ECs}=(\text { DDT cycles })+30 \times(\text { CDT cycles })
$$

According to this formula, a wheelchair would have to endure more than 400,000 cycles to pass the durability portion of the test. To contrast the cost-effectiveness of wheelchairs, we derived the value of a wheelchair by normalizing the number of ECs by the manufacturer's suggested retail price (unit of value $=$ cycles/dollar).

For details of the standards test methods, please refer to the ANSI/RESNA and ISO wheelchair standards tests [18-19].

\section{Data Analysis}

This study focused on test results of static stability; braking effectiveness; brake fatigue; and static, impact, and fatigue strength. Descriptive information and statistics for each test as well as wheelchair dimensions were collected. The coefficient of variation $(\mathrm{CV})$, the ratio of the standard deviation (SD) to the mean, was reported to reveal the scale of variation in the results. Because the sample sizes were small and not normally distributed at both the model and group levels, nonparametric statistical tests were chosen. The Kruskall-Wallis test and the Mann-Whitney test (nonparametric test for independent samples) were used to compare test results among the four AURW models. The Mann-Whitney test was used to compare static stability, ECs, and value between AURWs and TURWs and between AURWs and AUFWs. Because a discrepancy was observed in ECs and value between the rigid wheelchairs tested with high versus low pressure tires, the Mann-Whitney and Spearman correlation tests were performed to investigate the difference. The level of significance $(\alpha)$ was set as 0.05 a priori and was not adjusted for multiple tests because the power of this study was low as a result of the small sample size and large variance. To compare the durability among the AURWs, TURWs, and AUFWs, we used the Kaplan Meier method to plot the survival curves [13].

\section{RESULTS}

\section{Dimensions}

Chair dimensions of the AURWs are shown in Table 2. All the wheelchairs were tested with $610 \mathrm{~mm}$ (24 in.) wheels. However, the TiLite AeroZ and Quickie GT were tested with low pressure tires (recommended tire pressure: 75 psi) and the Invacare Crossfire and Kuschall AirPro were tested with high pressure tires (recommended tire pressure: 100-110 psi). Table 3 shows the tube dimensions and $F_{f}$ of each rigid wheelchair model. The frame tubes of the Kuschall AirPro had the lowest $F_{f}$ and the smallest wall thickness among the AURWs.

\section{Static Stability}

Table 4 shows the results of the static stability tests. The Kuschall AirPro wheelchairs demonstrated significantly different static stability from other models in both forward and rearward directions. During the rearward stability test (in the least stable configuration with the

Table 2 .

Overall mean dimensions of aluminum ultralight rigid wheelchair (AURW) models used in study.

\begin{tabular}{lcccc}
\hline \multicolumn{1}{c}{ Dimension } & TiLite AeroZ & Invacare Crossfire & Quickie GT & Kuschall AirPro \\
\hline Length (mm) & 839 & 810 & 835 & 905 \\
Width (mm) & 581 & 634 & 784 & 579 \\
Height (mm) & 801 & 787 & 10 & 785 \\
Mass (kg) & 10 & 9.9 & 525 & 10 \\
Minimum Turning Radius (mm) & 548 & 388 & 1,135 & 1,176 \\
Turn Around Between Limited & 1,103 & 1,178 & \\
$\quad$ Walls (mm) & & \\
Note: Measurements are significantly different between AURWs and titanium ultralight rigid wheelchairs $(p<0.05)$. & \\
\hline \hline
\end{tabular}


JRRD, Volume 47, Number 5, 2010

Table 3.

Frame tube dimensions (in millimeters) and estimated load at fracture $\left(F_{f}\right)$ (in newtons) of tubes without screw holes when load is applied at midpoint of tube.

\begin{tabular}{|c|c|c|c|c|c|c|c|c|}
\hline \multirow[b]{2}{*}{ Tube Dimension } & \multicolumn{4}{|c|}{ Aluminum Ultralight Rigid Wheelchair } & \multicolumn{4}{|c|}{ Titanium Ultralight Rigid Wheelchair* } \\
\hline & $\begin{array}{l}\text { TiLite } \\
\text { AeroZ }\end{array}$ & $\begin{array}{l}\text { Invacare } \\
\text { Crossfire }\end{array}$ & $\begin{array}{l}\text { Quickie } \\
\text { GT }\end{array}$ & $\begin{array}{c}\text { Kuschall } \\
\text { AirPro }\end{array}$ & $\begin{array}{c}\text { Invacare } \\
\text { TopEnd }\end{array}$ & $\begin{array}{c}\text { Invacare } \\
\text { A4 }\end{array}$ & $\begin{array}{c}\text { Quickie } \\
\text { Ti }\end{array}$ & $\begin{array}{c}\text { TiLite } \\
\text { ZRA }\end{array}$ \\
\hline Outer Diameter & 31.9 & 28.9 & 28.9 & 30.3 & 25.7 & 25.7 & 25.7 & 31.8 \\
\hline Inner Diameter & 26.7 & 22.3 & 22.3 & 26.1 & 23.1 & 23.1 & 23.1 & 28.8 \\
\hline Wall Thickness & 2.6 & 3.3 & 3.3 & 2.1 & 1.3 & 1.3 & 1.3 & 1.5 \\
\hline$F_{f}$ & 448 & 422 & 422 & 339 & 509 & 509 & 509 & 909 \\
\hline
\end{tabular}

${ }^{*}$ Liu HY, Cooper RA, Pearlman J, Cooper R, Connor S. Evaluation of titanium ultralight manual wheelchairs using ANSI/RESNA standards. J Rehabil Res Dev. 2008;45(9):1251-68. [PMID: 19319751] DOI:10.1682/JRRD.2007.12.0204

Table 4.

Tipping angles (in degrees) of aluminum ultralight rigid wheelchairs from static stability tests (mean \pm standard deviation [SD], coefficient of variation $[\mathrm{CV}])$.

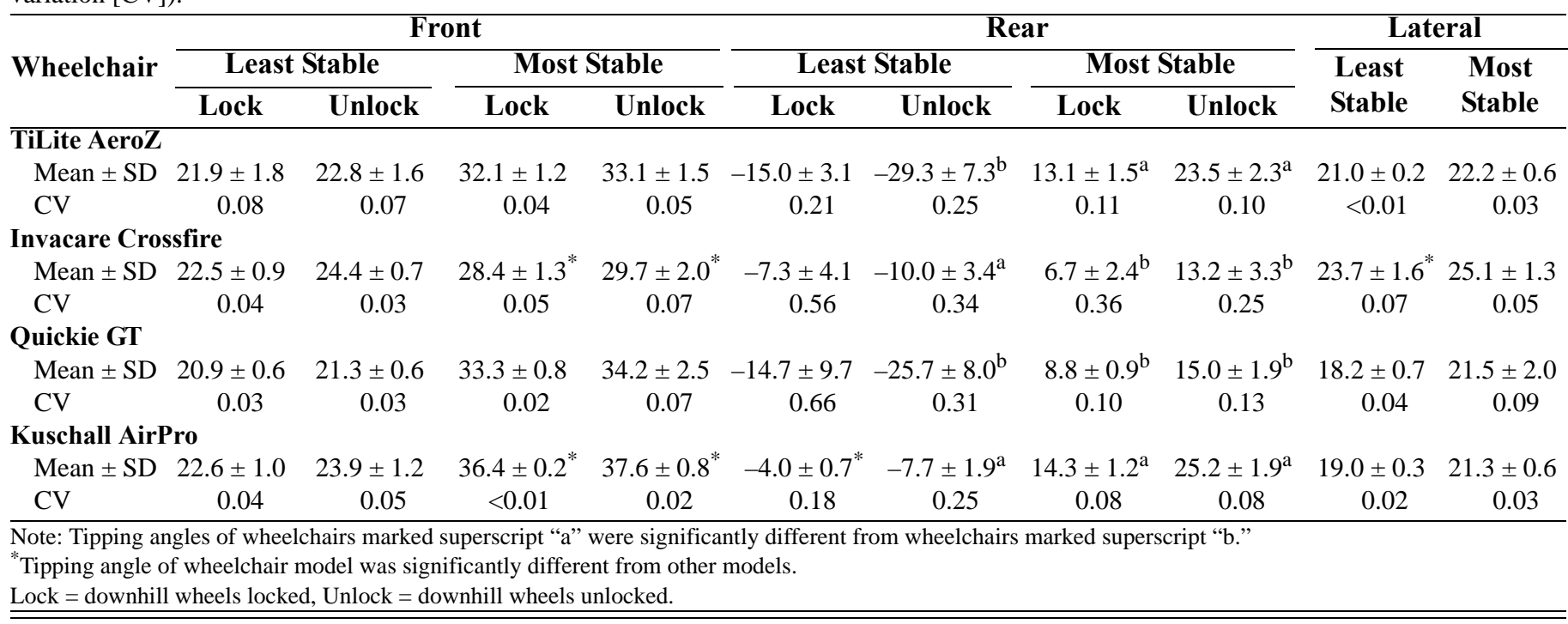

rear wheels unlocked), the casters of one Quickie GT wheelchair had not touched the platform by the time the slope had risen to $34.9^{\circ}$. Due to safety concerns, we stopped the test and recorded the angle as $-34.9^{\circ}$.

\section{Braking Effectiveness}

Table 5 shows the results of the braking effectiveness tests. The forward braking effectiveness angles were recorded when the wheelchair started sliding or rolling downhill. Two Invacare Crossfires and one Kuschall AirPro slid, and the remainder of the chairs rolled during the forward braking effectiveness test. No significant differences were noted in forward braking effectiveness angles among the four AURW models. The results of the rearward braking effectiveness test were tipping angles because all the AURWs tipped without sliding or rolling.
Table 5.

Tipping or sliding angles (in degrees) of aluminum ultralight rigid wheelchairs in braking effectiveness tests.

\begin{tabular}{lccccc}
\hline \multirow{2}{*}{ Wheelchair } & \multicolumn{2}{c}{ Forward } & & \multicolumn{2}{c}{ Rearward } \\
\cline { 2 - 3 } $\begin{array}{l}\text { TiLite } \\
\text { AeroZ }\end{array}$ & $11.7 \pm 2.9$ & 0.25 & & $11.9 \pm 1.6{ }^{*}$ & 0.13 \\
$\begin{array}{l}\text { Invacare } \\
\text { Crossfire }\end{array}$ & $14.7 \pm 1.9$ & 0.13 & & $5.2 \pm 1.5$ & 0.29 \\
$\begin{array}{l}\text { Quickie } \\
\text { GT }\end{array}$ & $15.9 \pm 1.1$ & 0.07 & & $5.5 \pm 0.3$ & 0.05 \\
$\begin{array}{l}\text { Kuschall } \\
\text { AirPro }\end{array}$ & $13.9 \pm 5.1$ & 0.37 & $7.1 \pm 0.9$ & 0.13 \\
$\begin{array}{l}\text { Note: Forward = forward effectiveness test and rearward = rearward effective- } \\
\text { ness test. } \\
\text { * Significant difference was found among four wheelchair models. }\end{array}$ \\
CV = coefficient of variation, SD = standard deviation. \\
\hline \hline
\end{tabular}


The TiLite AeroZ had the largest tipping angle in the rearward braking effectiveness test $(p=0.05)$.

\section{Brake Fatigue}

All the AURWs completed 60,000 cycles in the brake fatigue test. No brakes shifted position during the test, and all were still functional after the test. Figure 3 shows a photograph of the kind of linkage system found in the TiLite AeroZ and Quickie GT brakes. The washer between link $\mathrm{A}$ and link $\mathrm{B}$ at joint 4 wore out during the test, and therefore, the brake-engagement movement was not smooth by the end of the test. The Invacare Crossfire also showed this type of failure as a consequence of a worn out washer on the parking brakes, even though it had a slightly different brake design from the other two models. The Kuschall AirPro wheelchairs had metal washers in their brakes. The metal washer on two chairs of this model also wore out, but this had less impact on the brake-engagement movement than in the other models.

\section{Impact and Static Strength}

All the AURWs passed the impact strength tests, but all the Invacare Crossfire chairs failed the static strength tests because their armrest mounting plates deformed after a $760 \mathrm{~N}$ downward force was applied to the armrests. This force caused the armrests to bend outward, which would impede the propulsion movement of the wheelchair user's hands (Figure 4).

\section{Fatigue}

The ECs and value of each wheelchair model are shown in Table 6. The TiLite AeroZ and Quickie GT had
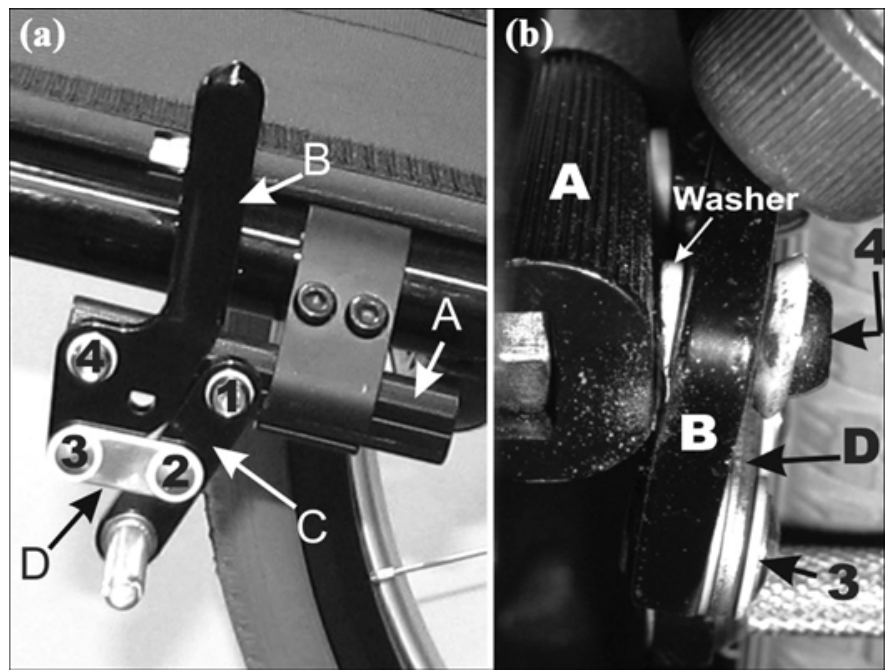

Figure 3.

Alignment of parking brake after brake fatigue test. TiLite AeroZ and Quickie GT had same type of brakes as shown here. (a) Side view of brake and (b) close-up of front view. Link A is base link clamped on frame tube. Link B is driving link where user applies force to engage brake. Link $\mathrm{C}$ is driving link where brake applies force on tire. Link D is coupler link. Four linkage joints are numbered from 1 to 4 counterclockwise. Washer between Link A and Link B at joint 4 wore out, and therefore, Link B was tilting with respect to Link A. Link A did not shift its position in relation to frame tube.

higher ECs and value but smaller CVs than the Invacare Crossfire and Kuschall AirPro. Figure 5 illustrates the ECs of each wheelchair. Seven AURWs passed the fatigue standard: three TiLite AeroZ, one Invacare Crossfire, and three Quickie GT. Please see the Appendix (available online only) for the failure modes of the AURWs in the fatigue tests.
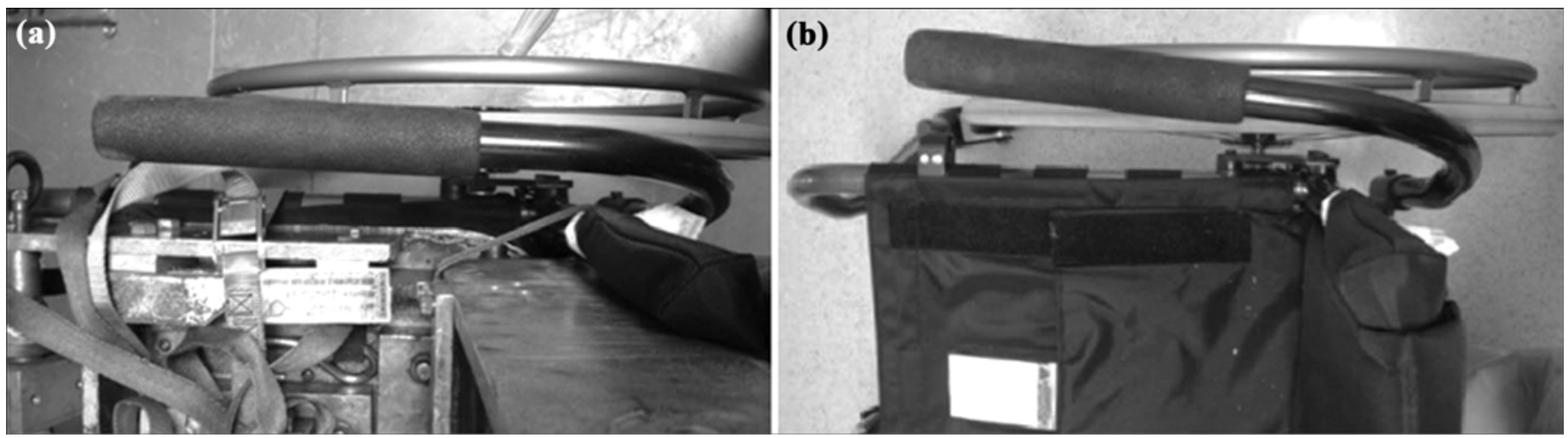

Figure 4.

Armrest alignment of Invacare Crossfire wheelchair. (a) Original alignment of armrest. (b) Alignment after $760 \mathrm{~N}$ downward force was applied on armrest in static strength test. 
JRRD, Volume 47, Number 5, 2010

Table 6.

Equivalent cycles (ECs) and cost-effectiveness (value) of each model of aluminum ultralight rigid wheelchair (mean \pm standard deviation [SD], coefficient of variation [CV]).

\begin{tabular}{lccccc}
\hline $\begin{array}{c}\text { Fatigue } \\
\text { Parameter }\end{array}$ & TiLite & $\begin{array}{c}\text { Invacare } \\
\text { Crossfire }\end{array}$ & $\begin{array}{c}\text { Quickie } \\
\text { GT }\end{array}$ & $\begin{array}{c}\text { Kuschall } \\
\text { AirPro }\end{array}$ & $\boldsymbol{p}_{\text {-Value* }}$ \\
\hline ECs (cycles) & AeroZ & & & & \\
Mean \pm SD & $499,721 \pm 32,923$ & $224,099 \pm 162,023$ & $469,342 \pm 64,843$ & $85,875 \pm 98,668$ & 0.03 \\
CV & 0.07 & 0.72 & 0.14 & 1.14 & - \\
Value (cycles/\$) & & & & 0.03 \\
Mean \pm SD & $218 \pm 14$ & $98 \pm 71$ & $205 \pm 28$ & $26 \pm 30$ & - \\
CV & 0.06 & 0.72 & 0.14 & 1.15 & - \\
*Significant differences $(p<0.05)$ were found between all wheelchair models for all comparisons except TiLite AeroZ and Quickie GT $(p=0.51$ for both ECs and \\
value) and Invacare Crossfire and Kuschall AirPro $(p=0.13$ and 0.28, respectively, for ECs and value).
\end{tabular}

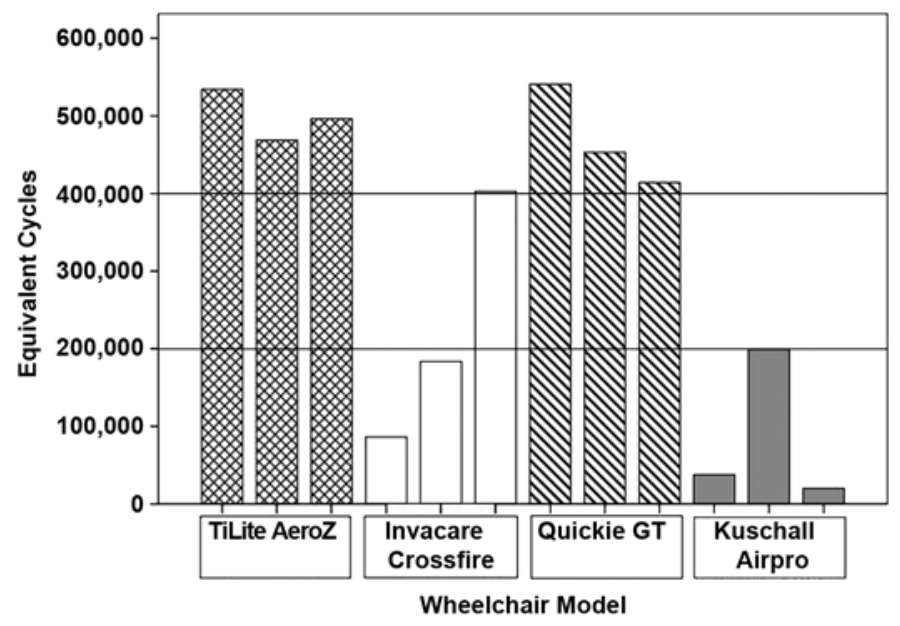

Figure 5.

Equivalent cycles (ECs) of each aluminum ultralight rigid wheelchair. Line at 200,000 ECs indicates required testing cycles in double-drum test. Line at 400,000 ECs represents minimum request in American National Standards Institute/Rehabilitation Engineering and Assistive Technology Society of North America wheelchair standard.

\section{DISCUSSION}

\section{Dimensions}

Table 7 illustrates the comparison of dimensions among the AURWs, TURWs, and AUFWs. Except for a significant difference in overall length, the AURWs and TURWs showed no difference in their overall width, height, or mass. AURWs and TURWs had similar dimensions and weights. Although a statistically significant difference was noted in the overall length, the actual difference was around $7 \mathrm{~cm}$. This difference may be because the Kuschall AirPro wheelchair design allows the rear axles to move farther rearward than the TURWs. However, the overall length could be decreased by simply changing the rear wheel axle position or wheel sizes.

The $F_{f}$ value of the Invacare TopEnd and A4 and the Quickie Ti was $509 \mathrm{~N}$, and the $F_{f}$ of the TiLite ZRA was $909 \mathrm{~N}$, calculated using the tube dimensions provided in the previous article [12]. Although the TURWs had stronger frame tubes than the AURWs, only three TURWs passed the fatigue standard. In contrast, seven AURW chairs passed the standard. These results suggest that more important factors than frame tube strength may affect wheelchair durability.

\section{Static Stability}

Table 8 shows the static stability test results of the AURWs, TURWs [12], and AUFWs [11]. All the groups had larger CVs in the tipping angles of the rearward stability tests than the forward and lateral stability tests. Because the AURWs and TURWs had similar dimensions and adjustments, they showed no difference in their stability, except in the forward direction in the most stable setting with front casters unlocked. The longer overall length of the AURWs could be the factor increasing the forward stability. The three groups of wheelchairs actually provide similar maximum rearward stability. As seen in the descriptive statistics, the AURWs and TURWs were more stable than the AUFWs in the forward direction. This may be the result of the rearward footrest position in the rigid chairs compared with the folding frame wheelchairs. However, our results only demonstrated possible ranges of wheelchair stability and can be a reference to compare wheelchairs of different groups. The actual stability of an everyday wheelchair is determined by the wheelchair setting, component selections (such as caster 
Table 7.

Wheelchair dimensions of AURWs, TURWs [1], and AUFWs [2].

\begin{tabular}{|c|c|c|c|c|c|c|}
\hline \multirow{2}{*}{ Dimension } & \multicolumn{2}{|c|}{ AURW } & \multicolumn{2}{|c|}{ TURW } & \multicolumn{2}{|c|}{ AUFW } \\
\hline & Mean \pm SD & $\mathbf{C V}$ & Mean \pm SD & $\mathbf{C V}$ & Mean \pm SD & $\mathbf{C V}$ \\
\hline Overall Length (mm) & $846 \pm 37^{*}$ & 0.04 & $814 \pm 12^{*}$ & 0.01 & $1,012 \pm 26$ & 0.02 \\
\hline Overall Width (mm) & $600 \pm 31$ & 0.05 & $604 \pm 66$ & 0.11 & $640 \pm 12$ & 0.02 \\
\hline Overall Height (mm) & $789 \pm 38$ & 0.05 & $762 \pm 45$ & 0.06 & $911 \pm 30$ & 0.03 \\
\hline Mass (kg) & $10.0 \pm 0.3$ & 0.03 & $10.0 \pm 1.0$ & 0.10 & $15.0 \pm 0.3$ & 0.02 \\
\hline
\end{tabular}

${ }^{*}$ Significant difference in overall length between AURW and TURW.

1. Liu HY, Cooper RA, Pearlman J, Cooper R, Connor S. Evaluation of titanium ultralight manual wheelchairs using ANSI/RESNA standards. J Rehabil Res Dev. 2008;45(9):1251-68. [PMID: 19319751] DOI:10.1682/JRRD.2007.12.0204

2. Cooper RA, Boninger ML, Rentschler A. Evaluation of selected ultralight manual wheelchairs using ANSI/RESNA standards. Arch Phys Med Rehabil. 1999; 80(4):462-67. [PMID: 10206612] DOI:10.1016/S0003-9993(99)90287-3

AUFW = aluminum ultralight folding wheelchair, AURW = aluminum ultralight rigid wheelchair, $\mathrm{CV}=$ coefficient of variation, $\mathrm{SD}=$ standard deviation, $\mathrm{TURW}=$ titanium ultralight folding wheelchair.

Table 8.

Tipping angles (in degrees) of AURWs, TURWs [1], and AUFWs [2] from static stability tests (mean \pm standard deviation [SD], coefficient of variation $[\mathrm{CV}])$.

\begin{tabular}{|c|c|c|c|c|c|c|c|c|c|c|}
\hline Wheelchair & \multicolumn{4}{|c|}{ Front } & \multicolumn{4}{|c|}{ Rear } & \multicolumn{2}{|c|}{ Lateral } \\
\hline \multicolumn{11}{|l|}{$\overline{\text { AURW }}$} \\
\hline $\mathrm{CV}$ & 0.06 & 0.06 & 0.10 & 0.10 & 0.66 & 0.64 & 0.32 & 0.30 & 0.11 & 0.08 \\
\hline \multicolumn{11}{|l|}{ TURW } \\
\hline Mean \pm SD & NA & $23.2 \pm 2.2$ & NA & $31.2 \pm 3.0$ & $-10.3 \pm 7.2$ & $-13.3 \pm 10.0$ & $11.6 \pm 2.5$ & $21.7 \pm 4.3$ & $21.6 \pm 1.3$ & $23.3 \pm 2.3$ \\
\hline Mean \pm SD & NA & $19.8 \pm 1.1^{\dagger}$ & NA & $20.0 \pm 1.1^{\dagger}$ & $3.2 \pm 3.5^{\dagger}$ & $8.25 \pm 2.9^{\dagger}$ & $10.8 \pm 2.7$ & $18.3 \pm 3.7$ & $19.2 \pm 0.9$ & $19.9 \pm 1.3^{\dagger}$ \\
\hline $\mathrm{CV}$ & NA & 0.06 & NA & 0.06 & 1.09 & 0.35 & 0.25 & 0.20 & 0.05 & 0.07 \\
\hline
\end{tabular}

*Significant difference was found between AURWs and TURWs.

${ }^{\dagger}$ Significant difference was found between rigid and folding frame chairs.

1. Liu HY, Cooper RA, Pearlman J, Cooper R, Connor S. Evaluation of titanium ultralight manual wheelchairs using ANSI/RESNA standards. J Rehabil Res Dev. 2008;45(9):1251-68. [PMID: 19319751] DOI:10.1682/JRRD.2007.12.0204

2. Cooper RA, Boninger ML, Rentschler A. Evaluation of selected ultralight manual wheelchairs using ANSI/RESNA standards. Arch Phys Med Rehabil. 1999;80(4):462-67. [PMID: 10206612] DOI:10.1016/S0003-9993(99)90287-3

AUFW = aluminum ultralight folding wheelchair, AURW = aluminum ultralight rigid wheelchair, Lock = downhill wheels locked, NA = not applicable, TURW = titanium ultralight folding wheelchair, Unlock $=$ downhill wheels unlocked.

and wheel sizes), and interaction with the weight distribution of the user.

The AURWs and TURWs were less stable in the rearward direction when they were set in their least stable configuration. This result could be attributed to their wider range of adjustability for the center of gravity (CoG). The proper adjustability and position of CoG vary with individual differences and needs. Kirby and Dupuis measured rearward tipping angles of 95 users sitting in their everyday wheelchairs without changing their configurations [21]. The mean $( \pm S D)$ rearward tipping angle when the occupants sat with neutral posture was $12.3^{\circ}$ $\left( \pm 3.0^{\circ}\right)$. The wide range of CoG adjustment in this study may be more than is needed. A variety of wheelchair adjustments are necessary to fit any individual; however, a highly adjustable wheelchair requires accurate assessment to maximize maneuverability and match users' preferences with stability requirements. Other than static stability, multiple factors could affect the risk of a rear-tipping accident, including body position, wheelchair skill, wheelchair frame design, and maintenance checks [2223]. Clinicians should use our test results as a reminder that an ultralight rigid wheelchair could be extremely unstable with certain adjustments.

The rearward stability tests had larger variances, especially when the wheelchairs were tested in their least 
stable configurations. The variances within the same group of wheelchairs could be explained by the difference in the adjustability among models. The variances within the same model of AURWs and TURWs may be due to uncontrolled deviations of the modified test methods. Because the wheelchairs were extremely unstable when they were set in the least stable configurations, we attached additional straps on the wheelchairs for safety.

\section{Braking Effectiveness}

Table 9 shows the test results of the AURWs and TURWs [12] in the braking effectiveness tests. The AURWs and TURWs had similar results in the braking effectiveness tests because the chairs had similar geometry and dimensions. Because the chairs tipped before sliding or rolling, the angles measured in the rearward braking effectiveness test were the chairs' tipping angles resulting from the rearward stability. Brake performance was not fully revealed by the tests. More research is needed to find out the appropriate modified test method to measure the rearward braking effectiveness of ultralight rigid wheelchairs.

\section{Brake Fatigue}

All the brakes were functional after the fatigue test. However, washers were worn out and all linkages between brake components were loose, and therefore, the excursion of the brake handle veered. Although no systematic survey or study about usage of parking brakes has been reported in the literature, in online forums, users commonly complain that their brakes require frequent adjustments [24]. Due to loss of selected muscle strength according to level of injury or diagnosis, a user may have

Table 9.

Tipping or sliding angles (in degrees) of AURWs and TURWs [1] in braking effectiveness tests.

\begin{tabular}{|c|c|c|c|c|}
\hline \multirow{2}{*}{$\begin{array}{c}\text { Wheelchair } \\
\text { Type }\end{array}$} & \multicolumn{2}{|c|}{ Forward } & \multicolumn{2}{|c|}{ Rearward } \\
\hline & $\overline{\text { Mean } \pm \text { SD }}$ & CV & $\overline{\text { Mean } \pm \text { SD }}$ & $\mathbf{C V}$ \\
\hline AURW & $14.0 \pm 3.1$ & 0.22 & $7.4 \pm 3.0$ & 0.40 \\
\hline TURW & $17.2 \pm 7.4$ & 0.43 & $7.3 \pm 3.7$ & 0.51 \\
\hline \multicolumn{5}{|c|}{$\begin{array}{l}\text { AURW = aluminum ultralight rigid wheelchair, CV = coefficient of variation, } \\
\text { SD = standard deviation, TURW = titanium ultralight rigid wheelchair. } \\
\text { 1. Liu HY, Cooper RA, Pearlman J, Cooper R, Connor S. Evaluation of tita- } \\
\text { nium ultralight manual wheelchairs using ANSI/RESNA standards. J Reha- } \\
\text { bil Res Dev. 2008;45(9):1251-68. [PMID: 19319751] } \\
\text { DOI:10.1682/JRRD.2007.12.0204 }\end{array}$} \\
\hline
\end{tabular}

to perform a particular movement pattern to operate parking brakes. When parking brakes become loose and handle excursions are shifted, the user needs to readjust brake position to match his/her functional movements. Users commonly push outward and forward to engage standard parking brakes, and the force tends to grind the washers and rotate the brake around the frame tube. However, the test system was set to operate the brake along its excursion, which may underestimate the effect of brake fatigue in the real world. On the other hand, changes in tire pressure and tread deterioration also alter the friction between the brake and tires, which can confound users. Further research is needed to determine primary factors that cause dissatisfaction with parking brakes.

\section{Impact and Static Strength}

The Invacare Crossfire wheelchairs had the same design and the same problem with the armrest mounting brackets as the Invacare wheelchairs in the titanium chair study [12]. This result showed that the strength of wheelchair components can be independent from the frame material and design. Besides improving quality of wheelchair frames, manufacturers should make efforts to design and analyze wheelchair components to ensure the safety and strength of the whole wheelchair.

\section{Fatigue}

Table 10 shows ECs and cost-effectiveness of the AURWs, TURWs [12], and AUFWs [11], and their survival curves are shown in Figure 6. Figure 7 shows interquartile ranges of ECs, which show that AUFWs [11] had larger EC variance across models than AURWs and TURWs [12], The AURWs were not significantly more durable than the TURWs, and therefore the hypothesis was rejected ( $p=0.15$ ).

The ECs and cost-effectiveness of the AUFWs were significantly different from the AURWs and TURWs; however, future studies are needed to test more chairs and verify the direction of difference. Although the descriptive statistics show that the AUFWs were more durable and cost-effective, AUFWs are not necessarily the better choice over AURWs and TURWs for all wheelchair users. AUFWs have different frame structures and provide different advantages than rigid frame chairs. Some users prefer ultralight folding wheelchairs because of the convenience of the folding mechanism and smoother rides resulting from larger caster sizes; others like rigid frames for their lighter weight and succinct design. Furthermore, the actual survival duration of a 
Table 10.

Equivalent cycles (ECs) and cost-effectiveness (value) of AURWs, TURWs [1], and AUFWs [2] (mean \pm standard deviation [SD], coefficient of variation [CV]).

\begin{tabular}{|c|c|c|c|}
\hline Fatigue Parameter & AURW & TURW & AUFW \\
\hline \multicolumn{4}{|l|}{ ECs (cycles) } \\
\hline Mean \pm SD & $319,759 \pm 199,634$ & $246,506 \pm 161,689$ & $1,092,441 \pm 730,624$ \\
\hline $\mathrm{CV}$ & 0.62 & 0.66 & 0.67 \\
\hline \multicolumn{4}{|l|}{ Value (cycles/\$) } \\
\hline Mean \pm SD & $137 \pm 90$ & $84 \pm 55$ & $673.3 \pm 506.5$ \\
\hline $\mathrm{CV}$ & 0.66 & 0.65 & 0.75 \\
\hline \multicolumn{4}{|c|}{ Jote: Significant differences $(p<0.01)$ were found between all three types of wheelchair models for all comparisons except AURWs and TURWs $(p=0.15$ and } \\
\hline \multicolumn{4}{|c|}{$\begin{array}{l}\text { 1. Liu HY, Cooper RA, Pearlman J, Cooper R, Connor S. Evaluation of titanium ultralight manual wheelchairs using ANSI/RESNA standards. J Rehabil Res Dev. } \\
\text { 2008;45(9):1251-68. [PMID: 19319751] DOI:10.1682/JRRD.2007.12.0204 }\end{array}$} \\
\hline \multicolumn{4}{|c|}{$\begin{array}{l}\text { 2. Cooper RA, Boninger ML, Rentschler A. Evaluation of selected ultralight manual wheelchairs using ANSI/RESNA standards. Arch Phys Med Rehabil. } \\
\text { 1999;80(4):462-67. [PMID: 10206612] DOI:10.1016/S0003-9993(99)90287-3 }\end{array}$} \\
\hline \multicolumn{4}{|c|}{ AUFW = aluminum ultralight folding wheelchair, AURW = aluminum ultralight rigid wheelchair, TURW = titanium ultralight rigid wheelchair. } \\
\hline
\end{tabular}

wheelchair can vary in terms of wheelchair configurations and the wheelchair user's skill. In addition to referring to the results of standards tests, consumers should receive clinical assessments and carefully consider their needs in order to decide between folding or rigid frames.

We strived to ensure that the test procedure and setting were equivalent across chairs, and thus smaller variance of ECs suggest that the wheelchairs were built with better quality control. However, the wheelchair models that had smaller variance of ECs were not necessarily more durable. For example, the TiLite ZRA had the smallest CV (0.38) but was the least durable among TURWs (Invacare TopEnd: 0.85; Quickie Ti: 0.68; Invacare A4: 0.49); conversely, the TiLite AeroZ and Quickie GT had smaller CVs and were more durable among AURWs.

The suggested pressure for tires and caster sizes are shown in Table 11. The wheelchair models tested with original equipment manufacturer (OEM) low pressure tires had larger average ECs (TiLite AeroZ, Quickie GT, Invacare A4, Quickie Ti) than the chairs tested with OEM high pressure tires, and the difference was significant ( $p=0.004$ ), with Spearman $r_{s}=0.60$ indicating that around 36 percent of the variance in ECs could be explained by tire pressure. The difference in value was also significant $(p=0.002)$, with Spearman $r_{s}=0.64$ indicating that around 41 percent of the variance in their values could be explained by tire pressure. Higher tire pressure can reduce shock absorption and therefore subject the chair to higher impact; however, not every wheelchair tested with lower pressure tires passed the standard. Tire pressure is one of the many factors that can influence the durability of a wheelchair. More specific research is needed to elaborate the relationship between tire pressure and wheelchair durability on different frame designs.

\section{Factors That Affect Fatigue Modes}

\section{Tire Pressure}

TiLite AeroZ and TiLite ZRA are identical in frame design and front casters. They all had fractures at the screw holes adjacent to the cantilever bends in the frame where the seat transitions into the footrest system. The TiLite AeroZ frame tubes lasted more than three times as long as the TiLite ZRA frame tubes. The major difference in wheelchair setup between the TiLite AeroZ and the TiLite ZRA is the tire pressure. Although the frame tubes of the TiLite AeroZ wheelchairs have smaller $F_{f}$ than the TiLite ZRA, the TiLite AeroZ wheelchairs were equipped with low pressure tires, which have better capacity for shock absorption than high pressure tires and therefore helped to reduce the impact stress on the frame during the fatigue tests. Although the screw holes near the cantilever bends were still the weakest points of the frames, the use of low pressure tires may have helped to extend the fatigue life.

\section{Modification to Reduce Influence of Stress Concentration Caused by Screw Holes}

The Quickie GT and Quickie Ti were equipped with the same tires and front casters and built with similar cantilever frame designs, but the Quickie GT was significantly more durable than the Quickie Ti $(p=0.05)$ and did not 


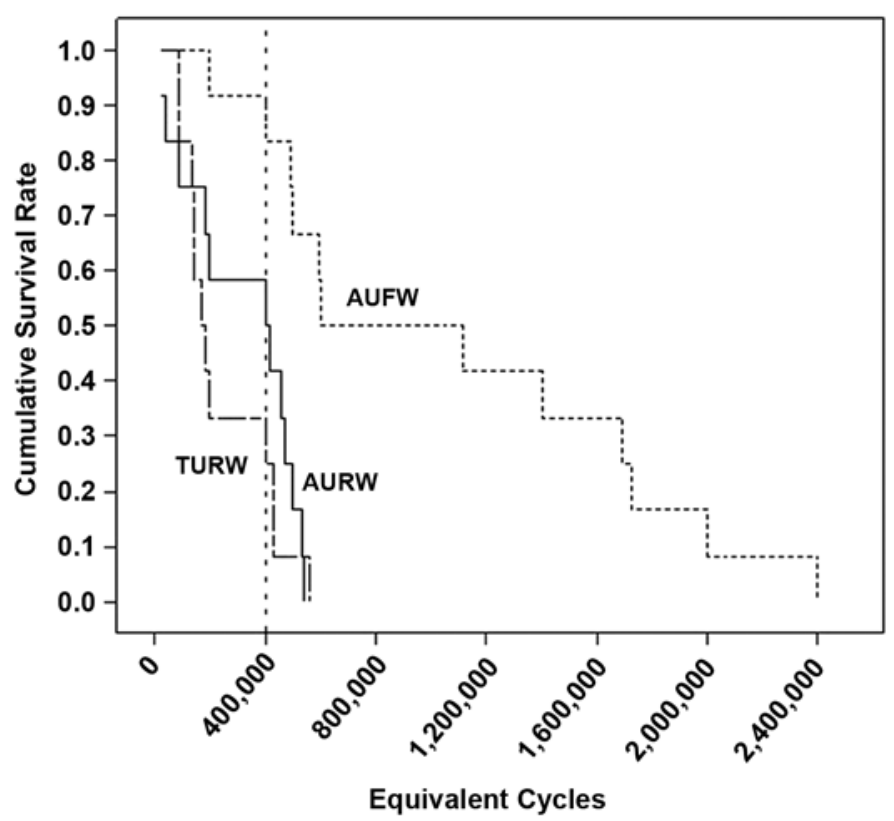

Figure 6.

Survival curves of aluminum ultralight rigid wheelchairs (AURWs), titanium ultralight rigid wheelchairs (TURWs), and aluminum ultralight folding wheelchairs (AUFWs). Dash line at 400,000 equivalent cycles indicates American National Standards Institute/ Rehabilitation Engineering and Assistive Technology Society of North America wheelchair fatigue standard. Data for TURWs from Liu HY, Cooper RA, Pearlman J, Cooper R, Connor S. Evaluation of titanium ultralight manual wheelchairs using ANSI/RESNA standards. J Rehabil Res Dev. 2008;45(9):1251-68. [PMID: 19319751] DOI:10.1682/ JRRD.2007.12.0204. Data for AUFWs from Cooper RA, Boninger ML, Rentschler A. Evaluation of selected ultralight manual wheelchairs using ANSI/RESNA standards. Arch Phys Med Rehabil. 1999;80(4): 462-67. [PMID: 10206612] DOI:10.1016/S0003-9993(99)90287-3.

fracture at the screw holes near the cantilever bends in the frame where the seat transitions into the footrest system. The frame tubes of the Quickie GT wheelchairs have smaller $F_{f}$ values than the Quickie Ti wheelchairs. The plastic saddles between the seat rails and frame tubes (Figure 8) may reduce the stress loading on the screw holes and therefore prevent or delay crack propagation through stress concentration. Adding plastic saddles may have compensated for inherent weakness of the cantilever structure and altered the stress concentration caused by screw holes near the cantilever bends in the frame where the seat transitions into the footrest system.

\section{Influence of Missed Assemblies}

The manufacturer may have forgotten to put washers on the camber tube support of an Invacare Crossfire

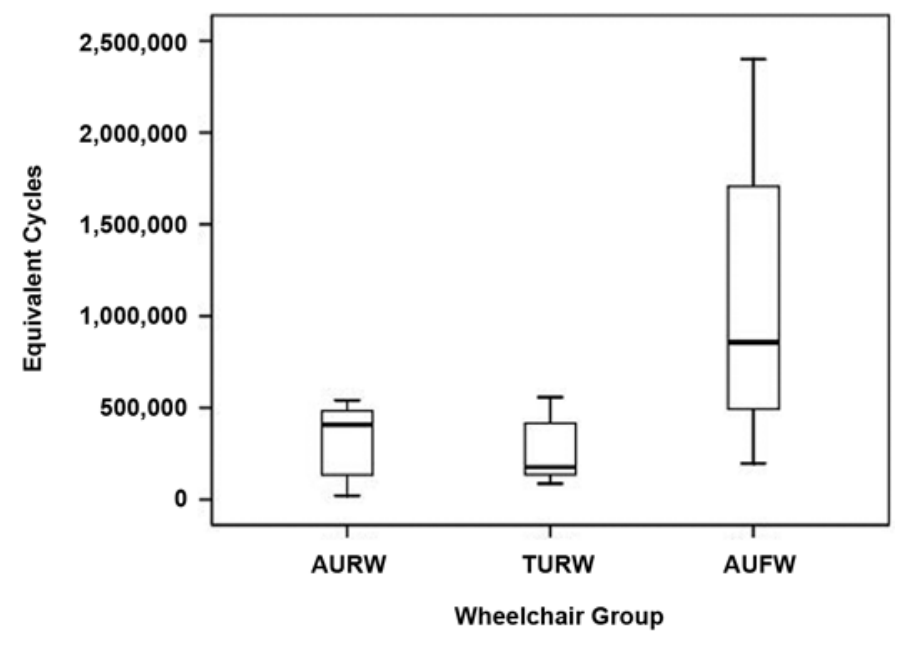

Figure 7.

Interquartile range of equivalent cycles (ECs) of aluminum ultralight rigid wheelchairs (AURWs), titanium ultralight rigid wheelchairs (TURWs), and aluminum ultralight folding wheelchairs (AUFWs). Box plot shows minimum (lower T-bar), first quartile (lower edge of box), median (horizontal line in box), third quartile (higher edge of box), and maximum (higher T-bar) ECs of each wheelchair group. Data for TURWs from Liu HY, Cooper RA, Pearlman J, Cooper R, Connor S. Evaluation of titanium ultralight manual wheelchairs using ANSI/RESNA standards. J Rehabil Res Dev. 2008;45(9):1251-68. [PMID: 19319751] DOI:10.1682/JRRD.2007.12.0204. Data for AUFWs from Cooper RA, Boninger ML, Rentschler A. Evaluation of selected ultralight manual wheelchairs using ANSI/RESNA standards. Arch Phys Med Rehabil. 1999;80(4):462-67. [PMID: 10206612] DOI:10.1016/S0003-9993(99)90287-3.

wheelchair while assembling the wheelchair, but we also made an oversight by not ensuring that the testing chairs were set up identically. We retained the fatigue test results of this wheelchair in the analysis because its number of ECs was similar to the other two Invacare Crossfires. However, we kept this study deviation in mind while looking at the test results. Suppliers and clinicians should note the importance of checking whether a wheelchair is properly assembled when it is delivered.

\section{Tube Manufacturing}

Buckling at the cantilever bends in the frame where the seat transitions into the footrest system was a failure mode that was not seen in the previous wheelchair comparison studies. Rupture lines were present at both sides of the buckled cantilever bends of the Kuschall AirPro wheelchairs. One of them followed the tube seam (Figure 9). Frame tubes of the Kuschall AirPro chairs were estimated to withstand less load at the fracture than other 
Table 11.

Suggested tire pressure of rear wheels and caster sizes when wheelchairs were tested [1-2].

\begin{tabular}{|c|c|c|c|c|c|c|c|c|c|}
\hline \multirow[b]{2}{*}{ Parameter } & \multicolumn{4}{|c|}{ AURW } & \multicolumn{4}{|c|}{ TURW } & \multirow[b]{2}{*}{$\begin{array}{c}\text { All } \\
\text { AUFW }\end{array}$} \\
\hline & $\begin{array}{l}\text { TiLite } \\
\text { AeroZ }\end{array}$ & $\begin{array}{l}\text { Invacare } \\
\text { Crossfire }\end{array}$ & $\begin{array}{l}\text { Quickie } \\
\text { GT }\end{array}$ & $\begin{array}{l}\text { Kuschall } \\
\text { AirPro }\end{array}$ & $\begin{array}{l}\text { Invacare } \\
\text { TopEnd }\end{array}$ & $\begin{array}{l}\text { Invacare } \\
\quad \text { A4 }\end{array}$ & $\begin{array}{l}\text { Quickie } \\
\text { Ti }\end{array}$ & $\begin{array}{l}\text { TiLite } \\
\text { ZRA }\end{array}$ & \\
\hline $\begin{array}{l}\text { Suggested Rear Tire } \\
\text { Pressure (psi) }\end{array}$ & 75 & 110 & 75 & 110 & 100 & 75 & 75 & 100 & 60 \\
\hline Caster Size (mm) & 80 & 80 & 80 & 70 & 80 & 80 & 80 & 80 & 203 \\
\hline \multicolumn{10}{|c|}{$\begin{array}{l}\text { 1. Cooper RA, Boninger ML, Rentschler A. Evaluation of selected ultralight manual wheelchairs using ANSI/RESNA standards. Arch Phys Med Rehabil. } \\
\text { 1999;80(4):462-67. [PMID: 10206612] DOI:10.1016/S0003-9993(99)90287-3 }\end{array}$} \\
\hline
\end{tabular}

AURW models (Table 3 ), and they were seamed tubes, which are potentially weaker than the extruded tubes that were used in the TiLite AeroZ and Quickie GT [25]. The wall thickness at the cantilever bends was thinner because of the bending stretch, which further decreased the tube strength at the location subject to bending stress. High pressure tires and small casters $(70 \mathrm{~mm})$ on the Kuschall AirPro wheelchairs resulted in less capacity for shock absorption and exposed the frame to higher impacts when negotiating obstacles. The combination of these factors made this model vulnerable to fatigue stress and induced buckling at the cantilever bends.

\section{Limitations}

To complete the wheelchair standards tests within a reasonable time frame and cost, we only tested three wheelchairs of each model for this study. For the models that had large variances in test results, more conclusive information may have been derived if more wheelchairs

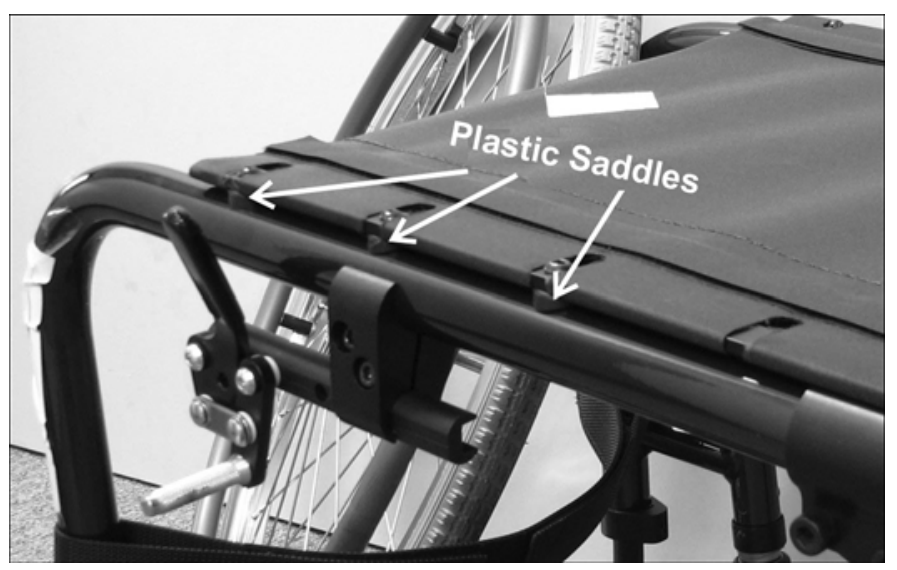

Figure 8.

Plastic saddle underneath seat rail on Quickie GT wheelchair. had been tested. Although we followed the testing methods of the wheelchair standards, intertester variability may have contributed to the variance. Some tests tended to result in larger variances across wheelchair models: for example, the static stability tests. To improve the problems related to cost and sample size, we are populating a longitudinal database, which will help us compile statistically relevant relationships between material type, frame type, and testing results.

All wheelchairs were purchased and tested in the manufacturer default configurations, which did not consist of exactly the same component sizes and selections, although we ordered the wheelchairs with the same seating dimensions. The results of this study serve as a reference to compare ultralight rigid frame wheelchairs. Various wheelchair settings will result in different performances and fatigue life.

\section{CONCLUSIONS}

Our testing results revealed some design and engineering questions and proposed some potential factors

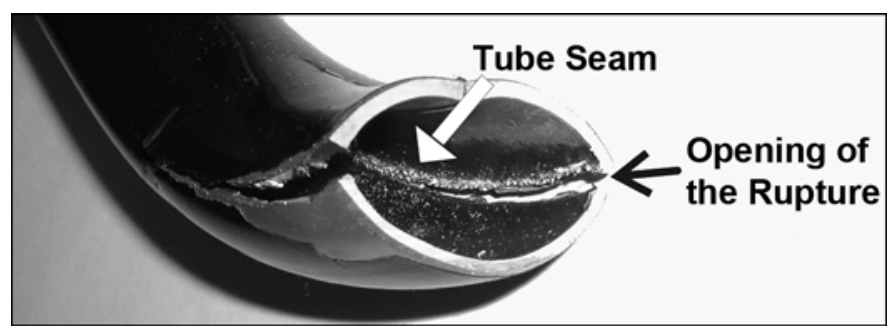

Figure 9.

Kuschall AirPro wheelchairs had rupture line at cantilever bend in frame where seat transitions into footrest system following tube seam. 
(tire pressure, tube-wall thickness, tube manufacturing) that could affect wheelchair durability. The frame material does not directly affect the performance and durability of aluminum versus titanium ultralight rigid wheelchairs, but proper wheelchair manufacturing and design based on the material properties are important. Although wheelchair performance in natural environments may vary from the test results because of different wheelchair settings and usage conditions, results of standards tests provide a baseline for equally comparing tested wheelchairs. Proper interpretation of the results contributes more detailed and objective information to consumers, clinicians, engineers, and manufacturers to select, set up, and design wheelchairs. Continuous research on wheelchair comparisons using wheelchair standards is essential to monitor the quality of wheelchair manufacturing and design.

\section{ACKNOWLEDGMENTS}

\author{
Author Contributions: \\ Study concept and design: J. Pearlman, R. A. Cooper. \\ Acquisition of data: H. Liu, E. Hong, H. Wang, B. Salatin. \\ Analysis and interpretation of data: H. Liu, J. Pearlman, R. Cooper, \\ R. A. Cooper. \\ Drafting of manuscript: H. Liu. \\ Statistical analysis: H. Liu. \\ Critical revision of manuscript for important intellectual content: \\ H. Liu, J. Pearlman, R. A. Cooper. \\ Obtained funding: R. A. Cooper. \\ Administrative, technical, or material support: E. Hong, H. Wang, \\ B. Salatin. \\ Study supervision: J. Pearlman, R. A. Cooper.
}

Financial Disclosures: The authors have declared that no competing interests exist.

Funding/Support: This material was based on work supported by VA Rehabilitation Research and Development Service (grant B3142C).

\section{REFERENCES}

1. Paralyzed Veterans of America Consortium for Spinal Cord Medicine. Preservation of upper limb function following spinal cord injury: A clinical guideline for health-care professionals. J Spinal Cord Med. 2005;28(5):434-70. [PMID: 16869091]

2. Kaye HS, Kang T, LaPlante MP. Mobility device use in the United States [Internet]. Washington (DC): National Institute on Disability and Rehabilitation Research; 2000 Jun [cited 2009 Dec]. Available from: http://dsc.ucsf.edu/pdf/ report14.pdf/.
3. Fitzgerald SG, Collins DM, Cooper RA, Tolerico M, Kelleher A, Hunt P, Martin S, Impink B, Cooper R. Issues in maintenance and repairs of wheelchairs: A pilot study. J Rehabil Res Dev. 2005;42(6):853-62. [PMID: 16680622] DOI:10.1682/JRRD.2004.10.0130

4. U.S. Food and Drug Administration (FDA). Recognized consensus standards. Silver Spring (MD): FDA; 2009 [updated 2009 Sep 9; cited 2009 Dec]. Available from: http://www.accessdata.fda.gov/SCRIPTs/cdrh/cfdocs/cfStand ards/Detail.CFM?STANDARD IDENTIFICATION $\mathrm{NO}=22292$.

5. U.S. Food and Drug Administration (FDA). Medical devices; Exemptions from premarket notification and reserved devices; Class I [Internet]. Fed Reg. 1998;63(21): 5387-93. Washington (DC): Federal Register Online via GPO Access; 1998 [cited 2009 Dec]. Available from: http://frwebgate.access.gpo.gov/cgi-bin/getdoc.cgi?IPaddress $=\& d b n a m e=1998$ register\&docid=98-2498-filed.

6. Sucher JF, Jones SL, Montoya ID. An overview of FDA regulatory requirements for new medical devices. Expert Opin Med Diagn. 2009;3(1):5-11. DOI:10.1517/17530050802644673

7. Guidance document for the preparation of premarket notification [510(k)] applications for mechanical and powered wheelchairs, and motorized three-wheeled vehicles [Internet]. Rockville (MD): U.S. Food and Drug Administration; 1995 [cited 2009 Dec]. Available from: http://www.fda.gov/downloads/MedicalDevices/Device

RegulationandGuidance/GuidanceDocuments/ucm080560.pdf/.

8. Cooper RA. Wheelchair standards: It's all about quality assurance and evidence-based practice. J Spinal Cord Med. 2006;29(2):93-94. [PMID: 16739552]

9. Cooper RA, Robertson RN, Lawrence B, Heil T, Albright SJ, VanSickle DP, Gonzalez J. Life-cycle analysis of depot versus rehabilitation manual wheelchairs. J Rehabil Res Dev. 1996;33(1):45-55. [PMID: 8868417]

10. Cooper RA, Gonzalez J, Lawrence B, Renschler A, Boninger ML, VanSickle DP. Performance of selected lightweight wheelchairs on ANSI/RESNA tests. American National Standards Institute-Rehabilitation Engineering and Assistive Technology Society of North America. Arch Phys Med Rehabil. 1997;78(10):1138-44. [PMID: 9339166] DOI:10.1016/S0003-9993(97)90141-6

11. Cooper RA, Boninger ML, Rentschler A. Evaluation of selected ultralight manual wheelchairs using ANSI/RESNA standards. Arch Phys Med Rehabil. 1999;80(4):462-67. [PMID: 10206612] DOI:10.1016/S0003-9993(99)90287-3

12. Liu HY, Cooper RA, Pearlman J, Cooper R, Connor S. Evaluation of titanium ultralight manual wheelchairs using ANSI/RESNA standards. J Rehabil Res Dev. 2008;45(9): 
1251-67. [PMID: 19319751]

DOI:10.1682/JRRD.2007.12.0204

13. Fitzgerald SG, Cooper RA, Boninger ML, Rentschler AJ. Comparison of fatigue life for 3 types of manual wheelchairs. Arch Phys Med Rehabil. 2001;82(10):1484-88. [PMID: 11588758] DOI:10.1053/apmr.2001.26139

14. Yamashita Y, Takayama I, Fujii H. Applications and features of titanium for automotive industry. Nippon Steel Tech Rep. 2002;375:85.

15. DiGiovine CP, Koontz AM, Boninger ML. Advances in manual wheelchair technology. Top Spinal Cord Inj Rehabil. 2006;11(4):1-14. DOI:10.1310/67TW-L3UD-RUYG-7UKJ

16. Boninger ML, Baldwin M, Cooper RA, Koontz A, Chan L. Manual wheelchair pushrim biomechanics and axle position. Arch Phys Med Rehabil. 2000;81(5):608-13.

[PMID: 10807100$]$

DOI:10.1016/S0003-9993(00)90043-1

17. Armstrong W, Borg J, Krizack M, Lindsley A, Mines K, Pearlman J, Reisinger K, Sheldon S. Guidelines on the provision of manual wheelchairs in less resourced settings. Geneva (Switzerland): World Health Organization; 2008.

18. American National Standards Institute (ANSI)/ Rehabilitation Engineering and Assistive Technology Society of North America (RESNA). American national standard for wheelchairs-Volume 1: Requirements and test methods for wheelchairs (including scooters). New York: ANSI; 1998.

19. International Organization for Standardization (ISO). Wheelchairs-Part 3: Determination of effectiveness of brakes. Geneva (Switzerland): ISO; 2003. ISO 7176-3:2003.

20. MatWeb Material Property Data [Internet]. Blacksburg (VA): Automation Creations, Inc; 2009. [updated 2009; cited 2009 Dec]. Available from: http://www.matweb.com/ search/search.aspx/.

21. Kirby RL, Dupuis DJ. Clinical measurement of the static rear stability of occupied wheelchairs. Arch Phys Med
Rehabil. 1999;80(2):199-205. [PMID: 10025498]

DOI:10.1016/S0003-9993(99)90122-3

22. Kirby RL, Ackroyd-Stolarz SA, Brown MG, Kirkland SA, MacLeod DA. Wheelchair-related accidents caused by tips and falls among noninstitutionalized users of manually propelled wheelchairs in Nova Scotia. Am J Phys Med Rehabil. 1994;73(5):319-30. [PMID: 7917161] DOI:10.1097/00002060-199409000-00004

23. Hansen R, Tresse S, Gunnarsson RK. Fewer accidents and better maintenance with active wheelchair check-ups: A randomized controlled clinical trial. Clin Rehabil. 2004;18(6): 631-39. [PMID: 15473115] DOI:10.1191/0269215504cr777oa

24. United Spinal Association (USA) Tech Guide. A webguide to wheelchair \& assistive technology choices [Internet]. Jackson Heights (NY): 2009 [cited 2009 Dec]. Available from: http://www.usatechguide.org/.

25. O’Brien Analytical. Integrated solutions improving process accuracy: Seamless vs. welded tubing [Internet]. St. Louis (MO): O’Brien Analytical; 2003 [cited 2009 Dec]. Available from: http://www.obcorp.com/WorkArea/DownloadAsset.aspx?id=1432/.

Submitted for publication August 25, 2009. Accepted in revised form February 16, 2010.

This article and any supplementary material should be cited as follows:

Liu H, Pearlman J, Cooper R, Hong E, Wang H, Salatin B, Cooper RA. Evaluation of aluminum ultralight rigid wheelchairs versus other ultralight wheelchairs using ANSI/RESNA standards. J Rehabil Res Dev. 2010;47(5): 441-56.

DOI:10:1682/JRRD.2009.08.0137 
